\title{
A COMUNICAÇÃO CIENTÍFICA EM ARQUIVOLOGIA NO BRASIL COM TEMÁTICAS RELACIONADAS À TECNOLOGIA DIGITAL (2001- 2018)
}

\author{
THE SCIENTIFIC COMMUNICATION IN ARCHIVAL \\ SCIENCE IN BRAZIL WITH THEMES RELATED TO \\ DIGITAL TECHNOLOGY (2001-2018)
}

Cynthia Roncaglioa

\begin{abstract}
RESUMO
Introdução: Nas primeiras décadas do século XXI, mais precisamente entre 2001 e 2018, percebe-se por meio da comunicação científica brasileira da área de Arquivologia que o uso disseminado da tecnologia digital passa a influir cada vez mais nas reflexões teóricas, nas práticas e nas opções metodológicas arquivísticas. Objetivo: A partir de tal constatação, o objetivo do artigo é identificar no âmbito das inter-relações entre os arquivos, a Arquivologia e a tecnologia digital, quais são os temas que têm despertado o interesse da comunidade profissional e científica que escreve e divulga artigos relacionados ao assunto. Metodologia: A pesquisa é de caráter exploratório, de natureza descritiva e analítica, baseada em levantamento quantitativo e qualitativo de artigos científicos disponíveis nas revistas Acervo, Ágora e Arquivo \& Administração, publicadas entre os anos de 2001 a 2018. Resultados: Os resultados mostram que há um crescente interesse pelo tema, sobretudo relacionado às influências mútuas que podem existir entre os arquivos, a Arquivologia e a tecnologia digital. Conclusões: São vários os desafios teóricos e práticos em um contexto tecnológico disruptivo, seja pela própria trajetória da Arquivologia em interlocução com as áreas de informação e comunicação, seja pelas constantes novidades impostas pelo avanço tecnológico.
\end{abstract}

Descritores: Arquivologia. Tecnologia Digital. Revista Acervo. Revista Ágora. Revista Arquivo \& Administração.

\section{INTRODUÇÃO}

No Brasil da década de 1980 poucas eram as instituições arquivísticas e os profissionais de arquivos que vislumbravam o impacto que teria a informática

\footnotetext{
a Doutora em Meio Ambiente e Desenvolvimento pela Universidade Federal do Paraná (UFPR). Docente do Programa de Pós-Graduação em Ciência da Informação da Universidade de Brasília (PPGCInf-UnB). E-mail: cynthia.roncaglio@gmail.com.
} 
nas dinâmicas profissionais, sociais e técnicas sobre os documentos de arquivo, impacto que já naquele momento gerava transformações sociais em vários países do mundo, sobretudo nos países do norte. Este período foi marcado pelo processo de assimilação entre o advento da informática e a sua capacidade de alterar práticas, princípios, métodos e saberes arquivísticos.

$\mathrm{Na}$ década de 1990, com o advento da internet e da rede mundial de computadores, as transformações culturais resultantes das tecnologias da informação e comunicação ampliaram-se em diversos países, atingindo de forma generalizada a produção de documentos de arquivo na administração pública e nas empresas privadas. Surgiram então vários artigos sobre documentos eletrônicos/digitais ${ }^{1}$ no Brasil escritos por arquivistas e profissionais da área. Este é o caso, por exemplo, do artigo intitulado "As novas tecnologias da informação e o futuro dos arquivos", de José Maria Jardim (1992), que analisava o impacto das novas tecnologias sobre os princípios e práticas arquivísticas e exortava a comunidade arquivística brasileira a assumir o seu lugar na questão do gerenciamento dos documentos eletrônicos. Outros artigos, como o de Adelina Novaes e Cruz (1992), publicado no Boletim da Associação dos Arquivistas Brasileiros (AAB), discutia os aspectos a serem considerados pelo arquivista em relação à informática. Em 1994, Marilena Leite Paes escreve dois artigos sobre o tema, intitulados "Os arquivos e as novas tecnologias" e Os arquivos e os desafios de um mundo em mudanças". No mesmo ano, Ana Maria Camargo também escreve "Arquivo, documento e informação: velhos e novos suportes. Em 1997 foi produzida a primeira dissertação acadêmica com abordagem do assunto intitulada "O correio eletrônico e o impacto na formação dos arquivos empresariais: estudo dos casos da Shell e do Club Mediterranée", de Anna Carla Almeida Mariz. Observa-se, pois, um interesse acadêmico crescente na área de Arquivologia sobre temas então atinentes ao que se chamava, ainda com certa imprecisão diante de tantas novidades, de "novas

\footnotetext{
${ }^{1}$ Ao longo do artigo serão usados os termos documentos eletrônicos/digitais como sinônimos posto que até os anos de 1990, sobretudo, usava-se apenas o primeiro termo. No entanto, o termo "documentos eletrônicos" é usado aqui apenas para referir a "informação registrada, codificada em dígitos binários, acessível e interpretável por meio de sistema computacional" (CONSELHO ..., 2016), não abrangendo documentos de ambiente analógico.
} 
tecnologias", "documentos eletrônicos", "gestão de documentos eletrônicos", "inteligência artificial", "documentos virtuais", "arquivamento eletrônico", sistemas eletrônicos" etc.

Nas primeiras duas décadas do século XXI, mais precisamente entre 2001 e 2018, período abrangido pela pesquisa, percebe-se na comunicação científica nacional e estrangeira que o uso disseminado e consolidado da tecnologia digital passa a influir cada vez mais nas reflexões teóricas, nas práticas e nas opções metodológicas arquivísticas. Diante da constatação, e tendo em vista que a pesquisa faz parte de uma investigação mais ampla sobre as inter-relações entre os arquivos, a Arquivologia e a tecnologia digital, questiona-se no âmbito da comunicação científica brasileira, quais são os assuntos que têm despertado o interesse da comunidade profissional e científica que escreve e divulga artigos sobre o tema? Quais as possíveis contribuições dessas reflexões para o desenvolvimento da Arquivologia brasileira?

São tais perguntas norteadoras da investigação que, por meio de uma metodologia de caráter exploratório, analítico e descritivo, buscou abordar e analisar parte da comunicação científica sobre o tema arquivos, Arquivologia e tecnologia digital, ao longo de dezoito anos, com foco no levantamento quantitativo e qualitativo das publicações de artigos realizadas em três importantes revistas científicas brasileiras da área de Arquivologia e/ou áreas afins, a saber: Acervo, Revista do Arquivo Nacional (RJ); Revista Arquivo \& Administração (RJ); e Revista Ágora (SC).

A análise do material coletado nas revistas é de suma importância, tendo em vista que, de acordo com renomados autores da área de comunicação científica (MEADDOWS, 1999; ZIMAN, 1979 apud GOMES, 2013), esta é tão vital quanto o próprio desenvolvimento da pesquisa e dos seus resultados, das reflexões e dos ensaios decorrentes dela, e também porque a literatura de uma área só cumpre plenamente sua função quando alcança um público mais amplo, é avaliada pelos seus pares, recebe críticas, é citada etc.

Diante da realidade social e tecnológica em curso, entende-se que arquivistas e pesquisadores da área necessitam refletir e atuar, de forma crítica e diligente sobre as mudanças na sua área, mais ou menos afetadas e 
modificadas pelas mudanças tecnológicas digitais, em especial as Tecnologias de Informação e Comunicação (TICs), que podem contribuir decisivamente ao avanço e à inovação tanto do conhecimento científico quanto à resolução dos problemas práticos que enfrentam os arquivos.

\section{ADVENTO DA INFORMÁTICA E A SUA RELAÇÃO COM A ARQUIVOLOGIA}

Quais são as implicações no campo da Arquivologia causadas pela imersão da sociedade contemporânea na tecnologia digital? Sabe-se que, no mercado de trabalho, por exemplo, ter o domínio das ferramentas digitais é um pré-requisito básico para qualquer área. Assim também funciona com os profissionais da informação que foram profundamente atingidos no seu saberfazer, resultado de um avanço tecnológico que ao longo dos anos tem mudado os meios de produção e comunicação das informações e de registros das atividades profissionais e pessoais.

A Arquivologia, assim como outras áreas da informação e comunicação, tem lidado com os desafios de uma mudança oriunda do advento da Informática na década de 1960 e 1970. O contexto, fomentado pelos avanços da indústria eletrônica, provocou transformações culturais e sociais, que ganham neste século mais velocidade e um permanente dinamismo que atinge todas as áreas do conhecimento.

Em 1964, o tema "Arquivologia e Informática" é abordado pela primeira vez no Conselho Internacional de Arquivos (ICA) em um congresso internacional realizado em Paris. A então falta de recursos financeiros e o conservadorismo por parte dos profissionais da área quanto aos documentos eletrônicos pontuava a ausência de conhecimento dos impactos que as novas tecnologias teriam em todos os campos da Arquivologia, desde a sua forma de pensar até a sua produção, gestão, preservação e acesso (FISHBEIN, 1984).

$\mathrm{Na}$ década de 1970 ocorreu um processo de assimilação de procedimentos, dispositivos, métodos e técnicas que continuam trazendo novidades até os dias atuais, mudando significativamente o modo de pensar e 
de se fazer as coisas. Fishbein (1984) considerava também que haviam dúvidas e certa desconfiança quanto a se considerar documentos eletrônicos como passíveis de serem documentos de arquivo.

Para Rondinelli (2002), as relações entre Arquivologia e informática no Brasil da década de 1970 apresentavam um quadro peculiar, porque "[...] apesar de contar com um representante no então Comitê de Automação do CIA, os arquivistas brasileiros se limitavam a refletir sobre novas tecnologias, sempre a reboque de outros profissionais da informação." (RONDINELLI, 2002, p. 29). Com exceção de artigos publicados na revista Arquivo \& Administração, de autoria de profissionais da área de informação como Mont-Mor, Miranda Neto, Barreto e outros, a década se definia como o início de um vagaroso despertar para a possibilidade do uso de automação de arquivos (RONDINELLI, 2002). Ainda segundo a autora, na década de 1980, apesar de algumas poucas iniciativas concernentes ao uso da Informática nos arquivos, segundo Rondinelli, "a comunidade arquivista brasileira parece ter repetido o mesmo comportamento da década de 1970, isto é, ouviu muito e agiu pouco." (RONDINELLI, 2002, p. 31). Ou seja, poucas instituições arquivísticas e profissionais no país entendiam a decisiva presença da Informática nas dinâmicas profissionais, sociais e técnicas, e as consequentes mudanças na forma de se produzir, gerir, comunicar e acessar informações e documentos.

Na década de 1990, tanto em âmbito internacional quanto no Brasil, com a crescente transformação social e tecnológica, crescem os debates e a literatura sobre o tema, inclusive no Brasil como indicado na Introdução. O artigo de Charles Dollar (1994), traduzido no Brasil sob o título "O impacto das tecnologias de informação sobre os princípios e práticas de arquivos: algumas considerações" apresenta, de forma sucinta e didática, aspectos teóricos e práticos da disciplina arquivística que seriam profundamente modificados pela tecnologia digital e, nas décadas seguintes, cada vez mais incrementados. $O$ conceito de documento original e de ordem original, o princípio da proveniência, as principais funções arquivísticas (classificação, descrição e preservação) e as formas de mediação e acesso são alguns dos pontos explorados pelo autor (DOLLAR, 1994). 
A partir do século XXI, de acordo com Rondinelli (2002), ocorre uma série de iniciativas institucionais e acadêmicas, dentro e fora do Brasil, fruto deste enfoque no tema abordado nas décadas passadas, no sentido de aprofundar os estudos e buscar soluções que possibilitassem o uso mais eficiente das ferramentas tecnológicas para fazer a gestão dos documentos, preservar e dar acesso à memória digital.

A pesquisa ora apresentada, traz uma curta contribuição acerca dessas iniciativas no âmbito da comunicação científica da área no Brasil. Embora não seja exaustiva, revela tendências do pensamento arquivístico acerca das interfaces entre os arquivos, a Arquivologia e as tecnologias de informação e comunicação.

\section{METODOLOGIA}

De caráter descritivo e analítico, a metodologia se baseia em levantamento quantitativo e qualitativo das publicações de artigos em revistas selecionadas da área de arquivos e áreas afins que abrangem o período de 2001 a 2018.

As revistas científicas têm o objetivo de promover, difundir e publicar o progresso da ciência como um todo ou em seus mais específicos campos. Foram selecionadas três revistas para essa fase da pesquisa voltadas quase que exclusivamente para a divulgação de artigos produzidos por arquivistas ou por pesquisadores e profissionais de arquivos, exceto a Revista Acervo, publicada pelo Arquivo Nacional, que possui temáticas voltadas também para a área de História. Este foi o principal critério de seleção, neste momento da investigação, considerando ainda a qualidade dos textos publicados e a longa periodicidade das revistas.

A Revista Acervo é publicada pelo Arquivo Nacional. Lançada em 1986, sua periodicidade é quadrimestral. "A revista tem por objetivo divulgar estudos e fontes nas áreas de ciências humanas e sociais aplicadas, especialmente História e Arquivologia" (ACERVO, [2020], online). Insere-se no estrato Qualis 
Periódicos² B2 - classificação referente à avaliação no Quadriênio 2013-2016 na área de Comunicação e Informação da Coordenação de Aperfeiçoamento de Pessoal de Nível Superior (Capes).

A Revista Ágora é publicada desde 1985 e editada pela equipe do Departamento de Ciência da Informação da Universidade Federal de Santa Catarina (UFSC), com periodicidade semestral. É voltada para a área da Arquivologia e publica trabalhos cujos temas versam sobre administração de arquivos, arquivos digitais, tecnologia da informação aplicada aos arquivos, entre outros (ÁGORA, [2020], online). A revista recebeu, na avaliação do quadriênio 2013/2016 da CAPES, o estrato Qualis Periódicos B1, na área de Comunicação e Informação.

A terceira revista selecionada é Arquivo \& Administração, criada pela Associação dos Arquivistas Brasileiros, fundada em 20 de outubro de 1971, e voltada para temas relacionados aos profissionais de arquivo e da Arquivologia, com o intuito de promover a difusão do trabalho e do conhecimento arquivístico. (ARQUIVO NACIONAL, [2020], online).

A revista passou a ser editada em 1972 e teve suas atividades encerradas em 2014, com algumas interrupções nesse intervalo de anos. A Revista Arquivo \& Administração, segundo o Arquivo Nacional ([2020], online), "[...] constituiu-se no mais importante periódico científico brasileiro na área de Arquivologia.". Insere-se no estrato Qualis Periódicos B1, na área de Comunicação e Informação da Capes.

Para a coleta de dados foi feita primeiramente uma busca pelas seguintes palavras-chave: arquivo, Arquivologia, arquivística, documento digital, documento eletrônico, tecnologia. Num segundo momento, restringiu-se as palavras-chave a Arquivologia, arquivística, documento eletrônico e documento digital, posto que arquivo e tecnologia são termos muito amplos e trouxeram muitos resultados sem relação com a área. Após essa seleção foram coletados

\footnotetext{
${ }^{2}$ Qualis Periódicos "é um sistema usado para classificar a produção científica dos programas de pós-graduação no Brasil que se refere aos artigos publicados em periódicos científicos." (Plataforma Sucupira Capes, 2020). O atual modelo passou a ser aplicado no triênio 2007-2009. O estrato mais elevado é A1 seguido por A2, B1, B2, B3, B4, B5 e C, Ver detalhes em: https://sucupira.capes.gov.br/sucupira/public/index.xhtml. Acesso em: 19 jun.2020.
} 
os seguintes metadados a serem analisados; nome da revista; período de publicação; título do artigo; autor/a; palavras-chave; e resumo.

A partir dos títulos e resumos, e dos objetivos da pesquisa, foram criadas categorias de análise iniciais, intermediárias e finais. Toda a categorização foi feita conforme regras de orientação para elaboração e classificação de categorias de análise que, segundo Carlomagno e Rocha (2016) são:

1) [...] regras claras de inclusão e exclusão [...]; 2) [...] categorias [...] mutuamente excludentes; 3) [...] não muito amplas, sendo seu conteúdo homogêneo entre si; 4) [...] contemplar todos os conteúdos possíveis e a categoria "outro" deve ser residual; 5) [...] objetiva, não passível de ser codificada de forma diferente a depender a interpretação do analista." (CARLOMAGNO; ROCHA, 2016, p. 173).

As quatro categorias finais criadas para analisar os artigos são as seguintes:1) Relações entre os arquivos, a Arquivologia e a tecnologia digital (artigos que fazem uma investigação exploratória, sem propor aplicação de metodologias ou apresentar resultados práticos); 2) Influências mútuas entre os arquivos, a Arquivologia e a tecnologia digital (artigos que apresentam as influências da teoria, princípios, conceitos, atividades e metodologia arquivística na tecnologia digital e vice-versa); 3) Desafios teóricos e práticos (artigos relacionadas à produção, preservação, acesso aos documentos arquivísticos digitais e às necessidades dos profissionais e usuários); e 4) relatos de experiências (artigos que apresentam e descrevem usos da tecnologia digital nas atividades arquivísticas).

\section{RESULTADOS}

A tabulação dos dados foi realizada de modo a sistematizar as informações coletadas, com foco em agrupar e categorizar os artigos em relação ao objeto da pesquisa, a partir dos títulos e resumos, podendo com isso realizar a análise e observar o nível de incidência das publicações ao longo do recorte temporal estabelecido, tanto de cada revista quanto do grupo geral das três revistas selecionadas. Cabe salientar, todavia, que nem sempre os títulos e os resumos correspondem claramente ao conteúdo do texto, assim como em alguns números das revistas há artigos sem resumos. Sempre que necessário recorreu- 
se ao conteúdo do texto para demover dúvidas.

A seguir, no Gráfico 1, apresenta-se o resultado obtido nas três revistas por ano.

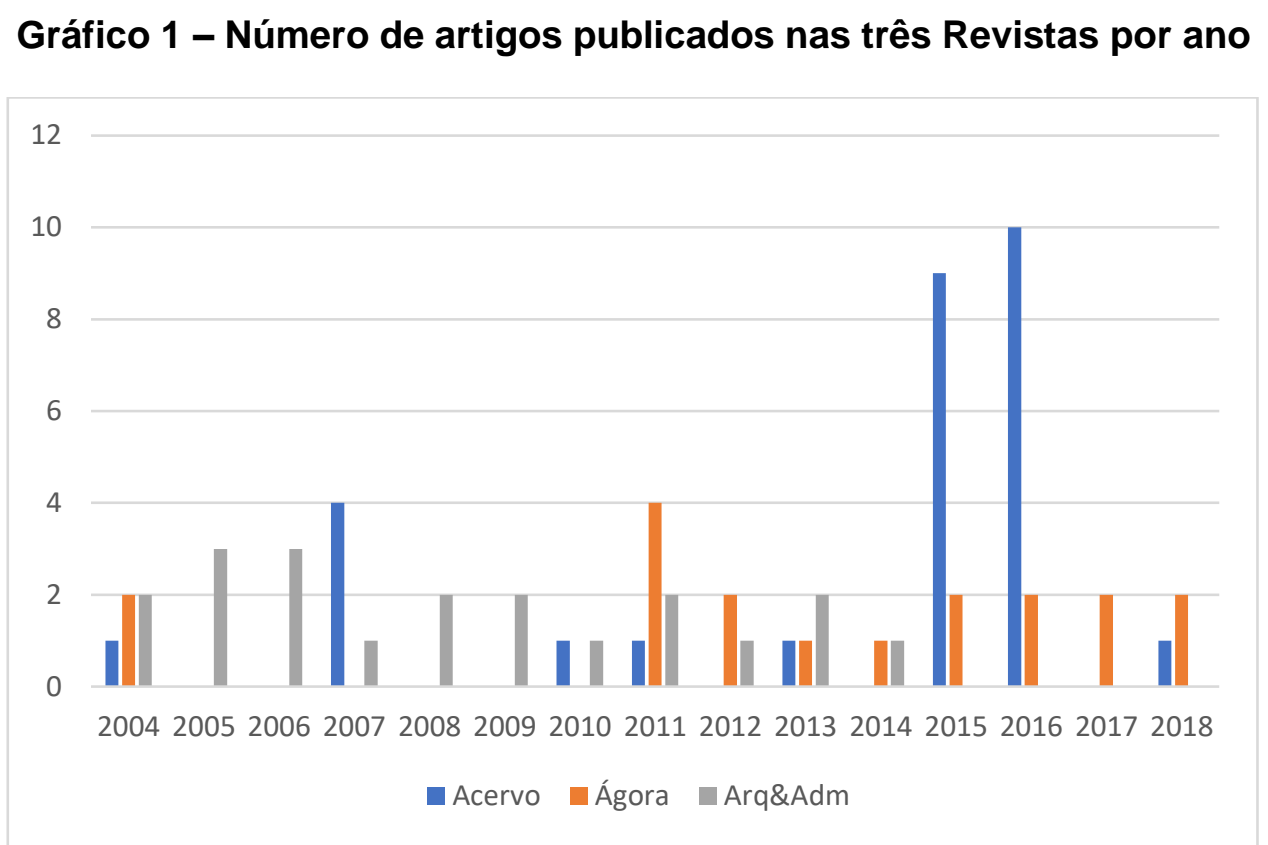

Fonte: Elaboração do autor.

Coincidentemente, os artigos referentes ao tema da pesquisa, nas três revistas, aparecem somente em 2004, sendo um na Revista Acervo, e dois, respectivamente na Revista Ágora e na Revista Arquivo \& Administração. Em 2005 e 2006 somente a Revista Arquivo \& Administração publicou três artigos, em cada ano, relacionados ao tema.

$\mathrm{Na}$ Revista Acervo, identifica-se um total de 28 artigos relacionados ao tema no período3 ${ }^{3}$. Destaca-se maior número de artigos entre os anos 2007 (quatro); 2015/2 (nove); e 2016/2 (dez). O tema do volume 28, número 2 da revista, publicado no segundo semestre de 2015, é "Gestão de documentos" (ACERVO, 2015), e o do volume 29, número 2 da revista, publicado no segundo semestre de 2016, é "Os arquivos na era digital" (ACERVO, 2016), o que pode justificar maior número de artigos nos referidos anos.

Na Revista Ágora, referente ao período analisado, foram publicados 18

\footnotetext{
${ }^{3}$ Não foi localizado nenhum número no ano de 2001 na versão eletrônica da revista utilizada para a pesquisa.
} 
artigos relacionados ao tema da pesquisa, sendo maior a incidência entre os anos de 2004 (dois), 2011/2 (três), 2015/2 (dois); 2016/2 (dois) e, em 2017 (dois). Entre o primeiro semestre de 2005 e o último de 2010 nenhum número foi lançado, o que justifica a ausência de publicações apontadas no gráfico no referido período.

Por fim, a Revista Arquivo \& Administração apresenta um total de 20 artigos publicados no período. Vale lembrar que as atividades desta revista foram encerradas em 2014, o que justifica a lacuna entre 2015 e 2018. Ainda assim, a quantidade de artigos publicados por esta revista supera, proporcionalmente, a quantidade de artigos publicados pelas outras duas revistas.

Cruzando os dados oriundos das três revistas, têm-se como resultado um total de 66 artigos publicados no período abordado. Observa-se que entre 2001 e 2018, ou mais precisamente, entre 2004 e 2018, há certa constância do tema nas revistas, mas não necessariamente um crescimento no número de artigos ao longo dos anos. Exceto quando se trata de números publicados exclusivamente para o tema, como ocorre no caso da Revista Acervo em 2015 e 2016, a média dos artigos varia entre 1, 2 e 1,86 por ano.

Considerando-se as transformações tecnológicas das décadas de 1980 e 1990 em âmbito internacional, que no Brasil, entre outras iniciativas, impulsionaram a implementação do governo eletrônico do Estado brasileiro, a partir do ano 2000, com o consequente, contínuo e intensivo uso das tecnologias de informação e comunicação (TICs) na administração pública, seria possível imaginar maior número de pesquisadores da área e arquivistas interessados no tema, posto que tanto a legislação como as práticas arquivísticas a partir de então seriam afetadas por essas mudanças.

No Quadro 1, a seguir, apresenta-se a quantidade de artigos coletados de cada revista segundo as categorias de análise. 
Quadro 1 - Número de artigos nas três Revistas de acordo com as categorias de análise

\begin{tabular}{|c|c|c|c|c|}
\hline Categorias & $\begin{array}{c}\text { Revista } \\
\text { Acervo }\end{array}$ & $\begin{array}{c}\text { Revista } \\
\text { Ágora }\end{array}$ & $\begin{array}{c}\text { Revista } \\
\text { Arquivo \& } \\
\text { Administração }\end{array}$ & $\begin{array}{c}\text { Total das } \\
\text { revistas }\end{array}$ \\
\hline $\begin{array}{c}\text { Relações entre arquivos, } \\
\text { Arquivologia e tecnologia digital }\end{array}$ & 3 & 2 & 4 & 09 \\
\hline $\begin{array}{c}\text { Influências mútuas entre arquivos, } \\
\text { Arquivologia e tecnologia digital }\end{array}$ & 12 & 6 & 5 & 23 \\
\hline Desafios teóricos e práticos & 9 & 3 & 5 & 17 \\
\hline Relatos de experiências & 4 & 7 & 6 & 17 \\
\hline Total & 28 & 18 & 20 & 66 \\
\hline
\end{tabular}

Fonte: Elaboração do autor.

Observa-se que a Revista Acervo exibe maior número de artigos na categoria "Influências mútuas entre arquivos, Arquivologia e tecnologia digital" (12) e na categoria "Desafios teóricos e práticos" (9). Em menor número aparecem artigos sobre "Relatos de experiências" (4) e "Relações entre arquivos, Arquivologia e tecnologia digital" (3).

Já a Revista Ágora apresenta maior número de artigos na categoria "Relatos de experiências" (7) e "Influências mútuas entre arquivos, Arquivologia e tecnologia digital" (6). Em menor quantidade aparecem artigos sobre "Desafios teóricos e práticos" (3) e "Relações entre arquivos, Arquivologia e tecnologia digital" (2).

Na Revista Arquivo \& Administração há maior número de "Relatos de experiências" (6), seguido de um empate entre artigos que tratam das "Influências mútuas entre arquivos, Arquivologia e tecnologia digital" (5) e "Desafios teóricos e práticos" (5). Em seguida "Relações entre arquivos, Arquivologia e tecnologia digital" (4). Nota-se, todavia, uma distribuição quase similar entre as categorias abordadas.

Tendo em conta a totalidade das revistas (66), a categoria que aparece em primeiro lugar, com maior número de artigos (23) é "Influências mútuas entre arquivos, Arquivologia e tecnologia digital", que abrange temas relacionados à 
influência da teoria, princípios, conceitos, atividades e metodologias arquivísticas na tecnologia digital e vice-versa. A guisa de exemplos reproduz-se no Quadro 2 alguns títulos das três revistas que foram vinculados a esta categoria.

\section{Quadro 2 - Exemplos de títulos de artigos que correspondem à categoria Influências mútuas entre Arquivologia e tecnologia digital}

\begin{tabular}{|c|c|c|c|}
\hline $\begin{array}{c}\text { Título } \\
\end{array}$ & Ano & Nome da Revista & Autor(es) \\
\hline $\begin{array}{l}\text { Governo eletrônico, gestão da } \\
\text { informação e exclusão } \\
\text { informacional }\end{array}$ & 2004 & $\begin{array}{c}\text { Arquivo \& } \\
\text { Administração }\end{array}$ & José Maria Jardim \\
\hline $\begin{array}{c}\text { Acesso eletrônico à } \\
\text { informação arquivística: } \\
\text { vantagens e potenciais das } \\
\text { normas de descrição }\end{array}$ & 2007 & Acervo & Nils Bruebach \\
\hline $\begin{array}{c}\text { Desenvolvimentos na } \\
\text { descrição arquivística: } \\
\text { algumas sugestões para o } \\
\text { futuro }\end{array}$ & 2007 & Acervo & Michael Cook \\
\hline $\begin{array}{c}\text { Deixando o cofre e } \\
\text { participando da festa: usando } \\
\text { as mídias sociais para } \\
\text { compartilhar as coleções } \\
\text { arquivísticas }\end{array}$ & $2011 / 2$ & $\begin{array}{c}\text { Arquivo \& } \\
\text { Administração }\end{array}$ & Kate Theimer \\
\hline $\begin{array}{c}\text { Documentos express: desafios } \\
\text { e riscos do acesso online a } \\
\text { documentos de arquivo }\end{array}$ & $2012 / 2$ & $\begin{array}{c}\text { Arquivo \& } \\
\text { Administração }\end{array}$ & Luciana Heymann \\
\hline $\begin{array}{c}\text { Recuperação de imagens } \\
\text { digitais e normalização } \\
\text { arquivística }\end{array}$ & $2013 / 1$ & Acervo & $\begin{array}{c}\text { Antonio Victor } \\
\text { Rodrigues Botão e } \\
\text { Rosali Fernandez } \\
\text { de Souza }\end{array}$ \\
\hline $\begin{array}{l}\text { A divulgação do patrimônio } \\
\text { documental dos arquivos } \\
\text { universitários das IFES da } \\
\text { região Sul do Brasil em } \\
\text { websites }\end{array}$ & $2015 / 2$ & Ágora & Daniel Flores \\
\hline $\begin{array}{c}\text { Reapropriação de arquivos } \\
\text { cinematográficos em tempos } \\
\text { de YouTube }\end{array}$ & $2016 / 2$ & Ágora & $\begin{array}{l}\text { Maiara de Arruda } \\
\text { Nascimento e } \\
\text { Glaucia Vieira } \\
\text { Ramos Konrad }\end{array}$ \\
\hline $\begin{array}{l}\text { Acervos digitais de jornais: } \\
\text { considerações a respeito da } \\
\text { recuperação da informação } \\
\text { sobre futebol }\end{array}$ & $2017 / 1$ & Ágora & $\begin{array}{l}\text { Ítalo Henrique } \\
\text { Alves, Renato } \\
\text { Tarciso Barbosa } \\
\text { de Souza }\end{array}$ \\
\hline
\end{tabular}

Fonte: Elaboração do autor.

Tais exemplos evidenciam vários artigos, de autores nacionais e estrangeiros, relacionados à normalização da descrição arquivística e às 
possibilidades de recuperação e acesso à informação e aos documentos de arquivo. Este foi um dos primeiros temas que no final dos anos 1980 mobilizou a comunidade arquivística internacional a pensar em normas internacionais de descrição arquivística tendo em vista a criação da rede mundial de computadores e a popularização da internet. Dollar (1994) já previa os desafios que os profissionais de arquivo teriam para atender pesquisadores cada vez mais exigentes. Os "arquivistas de referência", segundo o autor, "terão de dominar as complicações de sistemas complexos de informação, a fim de que possam ajudar os usuários a definir claramente as suas necessidades de informação e assisti-los" (DOLLAR, 1994, p. 18).

Em segundo lugar há um empate entre duas categorias: "Desafios teóricos e práticos" (17), que abrange artigos que refletem sobre a produção, a preservação e o acesso aos documentos arquivísticos digitais e as necessidades dos profissionais e usuários; e "Relatos de experiência" (17) que apresentam e descrevem usos da tecnologia digital nas atividades arquivísticas.

A seguir, nos Quadros 3 e 4, apresenta-se alguns títulos das três revistas que foram vinculados a esta categoria.

\section{Quadro 3 - Exemplos de títulos de artigos que correspondem à categoria Desafios teóricos e práticos}

\begin{tabular}{|c|c|c|c|}
\hline Título & Ano & Nome da Revista & Autor(es) \\
\hline $\begin{array}{c}\text { Rumo a uma teoria arquivística } \\
\text { de preservação digital: as } \\
\text { descobertas conceituais do } \\
\text { Projeto Interpares }\end{array}$ & $2005 / 1$ & $\begin{array}{c}\text { Arquivo \& } \\
\text { Administração }\end{array}$ & Luciana Heymann \\
\hline $\begin{array}{c}\text { Gestão arquivística e } \\
\text { preservação de documentos } \\
\text { digitais no Brasil: estado da arte }\end{array}$ & $2006 / 1$ & $\begin{array}{c}\text { Arquivo \& } \\
\text { Administração }\end{array}$ & $\begin{array}{c}\text { Rosely Curi } \\
\text { Rondinelli e } \\
\text { Claudia Lacombe } \\
\text { Rocha }\end{array}$ \\
\hline $\begin{array}{c}\text { Preservação de } \\
\text { correspondência: o e-mail em } \\
\text { laboratórios científicos e } \\
\text { tecnológicos }\end{array}$ & $2007 / 1$ & $\begin{array}{c}\text { Arquivo \& } \\
\text { Administração }\end{array}$ & $\begin{array}{c}\text { Maria Celina } \\
\text { Soares de Mello e } \\
\text { Silva Vera Lúcia } \\
\text { da Ascenção Rego } \\
\text { Howard Besser }\end{array}$ \\
\hline $\begin{array}{c}\text { Longevidade Digital } \\
\text { O microfilme e o digital: as duas } \\
\text { faces da preservação }\end{array}$ & $2011 / 2$ & Acervo & $\begin{array}{c}\text { Sandra Maria } \\
\text { Veríssimo Soares } \\
\text { e Marcos Galindo }\end{array}$ \\
\hline $\begin{array}{c}\text { O PDF/A na gestão de } \\
\text { documentos arquivísticos }\end{array}$ & $2011 / 2$ & Ágora & Luciane Paula Vital \\
\hline Archivematica como ferramenta & $2014 / 1$ & Ágora & Ezmir Dippe Elias, \\
\hline
\end{tabular}




\begin{tabular}{|c|c|c|c|}
\hline $\begin{array}{c}\text { para acesso e preservação } \\
\text { digital a longo prazo }\end{array}$ & & $\begin{array}{c}\text { Eugenio Andrés } \\
\text { Díaz Merino, } \\
\text { Adilson Luiz Pinto, } \\
\text { Marli Dias de } \\
\text { Souza Pinto e } \\
\text { Vilson João Batista }\end{array}$ \\
\hline $\begin{array}{c}\text { Preservação de documentos } \\
\text { arquivísticos digitais autênticos: } \\
\text { reflexões e perspectivas }\end{array}$ & $2015 / 1$ & Acervo & $\begin{array}{c}\text { Henrique Machado } \\
\text { dos Santos e } \\
\text { Daniel Flores }\end{array}$ \\
\hline $\begin{array}{c}\text { Repositórios para a } \\
\text { preservação de documentos } \\
\text { arquivísticos digitais }\end{array}$ & $2015 / 2$ & Acervo & $\begin{array}{c}\text { Claudia Lacombe } \\
\text { Rocha }\end{array}$ \\
\hline
\end{tabular}

Fonte: Elaboração do autor.

\section{Quadro 4 - Exemplos de títulos de artigos que correspondem à categoria Relatos de experiência}

\begin{tabular}{|c|c|c|c|}
\hline Título & Ano & Nome da Revista & Autor(es) \\
\hline $\begin{array}{l}\text { Tribunal de Contas do Estado } \\
\text { e a informação }\end{array}$ & $2004 / 2$ & Ágora & $\begin{array}{l}\text { Isabela Ribas } \\
\text { Cesar Portella e } \\
\text { Valéria Gouvêa } \\
\text { Ghanen }\end{array}$ \\
\hline $\begin{array}{c}\text { Digitalización para la } \\
\text { preservación del } \\
\text { archivo sonoro de Casa de las } \\
\text { Américas }\end{array}$ & $2005 / 1$ & $\begin{array}{c}\text { Arquivo \& } \\
\text { Administração }\end{array}$ & $\begin{array}{l}\text { Arien González } \\
\text { Crespo }\end{array}$ \\
\hline $\begin{array}{l}\text { Os desafios para desenvolver } \\
\text { um glossário comum para } \\
\text { diferentes países e línguas no } \\
\text { âmbito do Projeto Interpares 3: } \\
\text { alguns exemplos da } \\
\text { experiência do Team Brasil }\end{array}$ & $2009 / 1$ & $\begin{array}{c}\text { Arquivo \& } \\
\text { Administração }\end{array}$ & $\begin{array}{c}\text { Claudia Lacombe } \\
\text { Rocha }\end{array}$ \\
\hline $\begin{array}{l}\text { Tabela de temporalidade da } \\
\text { UFSC em formato eletrônico: } \\
\text { otimizando o sistema }\end{array}$ & $2011 / 1$ & Ágora & $\begin{array}{l}\text { Eliana Maria dos } \\
\text { Santos Bahia e } \\
\text { Ezmir Dippe Elias }\end{array}$ \\
\hline $\begin{array}{c}\text { Gerenciamento eletrônico de } \\
\text { documentos (GED): aplicação } \\
\text { na Universidade Federal de } \\
\text { Santa Catarina }\end{array}$ & $2012 / 2$ & Ágora & Ezmir Dippe Elias \\
\hline $\begin{array}{l}\text { Sistema PTA - Módulo de } \\
\text { eliminação de documentos } \\
\text { autuados (processos) }\end{array}$ & $2014 / 2$ & Ágora & $\begin{array}{l}\text { Rísia Conceição } \\
\text { Silva Lira e Gilmar } \\
\text { Silva de Lima }\end{array}$ \\
\hline $\begin{array}{c}\text { Os repositórios Dspace e } \\
\text { Archivematica para } \\
\text { documentos arquivísticos } \\
\text { digitais }\end{array}$ & $2016 / 2$ & Acervo & $\begin{array}{l}\text { Sérgio Renato } \\
\text { Lampert }\end{array}$ \\
\hline $\begin{array}{l}\text { Digitalização de jornais: uma } \\
\text { reflexão sobre desafios e } \\
\text { melhores práticas }\end{array}$ & $2016 / 2$ & Acervo & $\begin{array}{l}\text { Bruno Leal Pastor } \\
\text { de Carvalho }\end{array}$ \\
\hline $\begin{array}{l}\text { A fotografia como documento } \\
\text { arquivístico e seu lugar nos }\end{array}$ & $2017 / 1$ & Ágora & $\begin{array}{l}\text { Luana Carla de } \\
\text { Moura dos Santos }\end{array}$ \\
\hline
\end{tabular}


arquivos municipais: o Arquivo

Público da cidade de Belo Horizonte e Marisa Brascher

Fonte: Elaboração do autor.

$\mathrm{Na}$ categoria Desafios teóricos e práticos concentram-se os artigos cujo conteúdo revela a inquietação a respeito da preservação e segurança dos documentos de arquivo e da informação arquivística, que já existia em grande medida em relação aos documentos produzidos em papel. Na realidade digital, os riscos se tornaram mais perceptíveis, ou, ainda, mais complexos, exigindo dos pesquisadores e profissionais da área repensar a teoria e a metodologia arquivísticas. Equiparada a esse desassossego dos arquivistas diante dos desafios impostos pelas inovações tecnológicas, a categoria Relatos de experiências demonstra como os arquivistas enfrentam esses desafios na sua realidade profissional. Sob novos sistemas de informação e comunicação aparecem os velhos problemas de avaliar documentos, buscar consensos terminológicos, encontrar os melhores padrões de digitalização e recuperação, gerenciar eletronicamente os documentos, revisitar suportes da informação.

Em terceiro e último lugar, com um número bem menor de artigos (9) enquadram-se na categoria Relações entre arquivos, Arquivologia e tecnologia digital, artigos de caráter mais teórico e exploratório, sem propor aplicação de metodologias ou apresentar resultados práticos. A seguir, no Quadro 5, apresenta-se alguns exemplos de títulos incluídos nesta categoria.

Quadro 5 - Exemplos de títulos de artigos que correspondem à categoria Relações entre arquivos, Arquivologia e tecnologia digital

\begin{tabular}{|c|c|c|c|}
\hline Título & Ano & Nome da Revista & Autor(es) \\
\hline $\begin{array}{c}\text { Ciência e Tecnologia na } \\
\text { Preservação da Informação: } \\
\text { Um desafio político }\end{array}$ & $2004 / 2$ & Acervo & $\begin{array}{c}\text { Sérgio Conde de } \\
\text { Albite Silva }\end{array}$ \\
\hline $\begin{array}{c}\text { Falando sobre diferença: } \\
\text { percepções sobre unicidade e } \\
\text { identidade nos arquivos }\end{array}$ & $2011 / 1$ & $\begin{array}{c}\text { Arquivo \& } \\
\text { Administração }\end{array}$ & Geoffrey Yeo \\
\hline $\begin{array}{c}\text { A arquivística funcional e sua } \\
\text { contribuição para o } \\
\text { desenvolvimento de uma } \\
\text { disciplina contemporânea }\end{array}$ & $2012 / 1$ & Ágora & $\begin{array}{c}\text { Natália Bolfarini } \\
\text { Tognoli }\end{array}$ \\
\hline $\begin{array}{c}\text { A arquivística, os arquivistas e } \\
\text { os arquivos no Canadá }\end{array}$ & $2015 / 2$ & Acervo & Carol Couture \\
\hline
\end{tabular}




\begin{tabular}{|c|c|c|c|}
\hline $\begin{array}{c}\text { A custódia como guarda e } \\
\text { proteção aos arquivos: uma } \\
\text { abordagem etimológica }\end{array}$ & $2016 / 2$ & Acervo & Margareth Silva \\
\hline $\begin{array}{c}\text { Acervos documentais on-line, } \\
\text { práticas de memória e } \\
\text { experiências educacionais }\end{array}$ & $2016 / 2$ & Acervo & $\begin{array}{c}\text { Adriana Carvalho } \\
\text { Koyama }\end{array}$ \\
\hline $\begin{array}{c}\text { Aprender a ler entre bits: } \\
\text { autenticidade em arquivos } \\
\text { pessoais digitais }\end{array}$ & $2016 / 2$ & Acervo & $\begin{array}{c}\text { Jorge Phelipe } \\
\text { Lirade Abreu }\end{array}$ \\
\hline $\begin{array}{c}\text { O ciclo vital ante o documento } \\
\text { digital: o modelo records } \\
\text { continuum como recurso de } \\
\text { elucidação }\end{array}$ & $2016 / 2$ & Acervo & $\begin{array}{c}\text { Cássio Murilo } \\
\text { Alves Costa Filho }\end{array}$ \\
\hline $\begin{array}{c}\text { Gestão e preservação de } \\
\text { documentos arquivísticos } \\
\text { digitais: revisitando alguns dos } \\
\text { conceitos que as precedem }\end{array}$ & $2016 / 2$ & Acervo & $\begin{array}{c}\text { Claudia Lacombe } \\
\text { Rocha } \\
\text { e Rosely Curi } \\
\text { Rondinelli }\end{array}$ \\
\hline
\end{tabular}

Fonte: Elaboração do autor.

Esta categoria abrange textos que buscam aprofundar a discussão sobre princípios e conceitos inerentes à atividade arquivística, estabelecer diálogos com autores estrangeiros e com outras disciplinas em busca de uma reflexão mais abrangente e consistente do atual conhecimento arquivístico. Tais estudos são fundamentais para alicerçar e alimentar as pesquisas na área de Arquivologia bem como promover e estimular boas práticas. No entanto, como se pode observar no resultado desta pesquisa, há poucos estudos voltados nesta direção.

Concernente ao número de autores por artigos, a revista Acervo apresenta variação de um a três autores por artigo; a Revista Ágora, um a cinco; e, a Revista Arquivo \& Administração um a dois. Há contribuições de autores estrangeiros na Revista Acervo e na Revista Arquivo \& Administração. $\mathrm{Na}$ primeira são dez autores estrangeiros de sete países, a saber: Alemanha, Austrália, Canadá, Colômbia, Estados Unidos, Espanha e Inglaterra. Na segunda são sete autores de quatro países, a saber: Canadá, Cuba, Estados Unidos e Inglaterra.

\section{CONCLUSÕES}

A partir das décadas de 1960 e 1970, e com mais ênfase na de 1980 e 
1990, a tecnologia analógica passou a convergir com a tecnologia digital na maior parte do mundo afetando paulatinamente o modo de produção, organização e preservação dos documentos de arquivo assim como as possibilidades de acesso a eles. Se num primeiro momento os arquivistas foram um pouco refratários às "novas tecnologias", sem compreender a efetiva mudança cultural em curso, logo foram se apercebendo de que esse era um caminho sem volta, e que o uso das técnicas e tecnologias digitais teriam várias implicações no âmbito da organização das instituições arquivísticas, nos métodos de trabalho para avaliar e organizar documentos de arquivo, e no desenvolvimento do ensino e da pesquisa em Arquivologia.

A Arquivologia, na sua trajetória como disciplina científica, os arquivos, tanto no que se refere à estrutura das instituições quanto aos serviços ofertados e demandados, os arquivistas e demais profissionais e pesquisadores ligados à área, passaram a lidar diretamente com os resultados dessas transformações e com as consequências inevitáveis no processo de reconfiguração dos procedimentos arquivísticos.

Este artigo, que faz parte de uma pesquisa mais ampla sobre o tema, procurou mostrar como essas mudanças tem se refletido na comunicação científica brasileira da área no século XXI (2001-2018), a partir da análise de artigos de três periódicos, cada qual com o seu perfil individual, comprometidos com a difusão do conhecimento sobre os arquivos e a Arquivologia no Brasil.

A partir dos resultados obtidos, não há dúvida que há um crescente interesse pelos temas arquivos, Arquivologia e tecnologia digital, sobretudo relacionado às influências mútuas que podem existir entre os arquivos, a Arquivologia e a tecnologia digital, aos desafios teóricos e práticos diante do imperativo tecnológico e às experiências relatadas. Apenas por alguns exemplos aqui apontados, percebe-se que esse interesse se alastra por vários subtemas; abarca desde estudos de natureza exploratória sobre os meios tecnológicos atuais das redes sociais para a difusão dos arquivos (Youtube, Facebook, Twitter etc.) até pesquisas e ensaios tradicionais da área sob a luz das transformações tecnológicas (características dos suportes da informação, repositórios digitais e gestão de documentos, entre outros.). 
Constata-se, no entanto, por meio da amostra da comunicação científica na área de arquivos e da Arquivologia no Brasil que há poucos estudos de caráter exploratório sobre a relação entre os arquivos, Arquivologia e tecnologia digital. Estudos que apresentem, por exemplo, uma abordagem mais reflexiva e crítica sobre a própria história da Arquivologia em relação às transformações tecnológicas; as desigualdades de acesso a essas tecnologias tanto no Brasil quanto comparativamente em outros países; as consequências nos currículos do ensino de graduação e nas pesquisas de pós-graduação; uma possível reconfiguração da profissão diante da exigência de novas competências e habilidades.

Pode-se inferir, portanto, a necessidade de aprofundamento de estudos da história e da epistemologia arquivística diante das mudanças tecnológicas, fundamentais tanto para o próprio desenvolvimento da disciplina científica quanto para compreensão e ação diante dos processos econômicos, culturais e tecnológicos que alteram e transformam a produção de documentos e os meios de preservar e dar acesso a eles.

\section{AGRADECIMENTOS}

Agradeço a Eric Reili Tomé que desenvolveu a pesquisa sob minha orientação durante um projeto de Iniciação Científica e que levantou parcialmente os dados apresentados aqui entre os anos de 2001 e 2017, e à Fundação de Apoio à Pesquisa do Distrito Federal (FAP/DF).

\section{REFERÊNCIAS}

ACERVO. REVISTA DO ARQUIVO NACIONAL. Gestão de documentos. Rio de Janeiro: Arquivo nacional, v.28, n.2 (jul./dez.2015).

ACERVO. REVISTA DO ARQUIVO NACIONAL. Os arquivos na era digital. Rio de Janeiro: Arquivo nacional, v. 29, n. 2 (jul./dez.2016).

ACERVO. REVISTA DO ARQUIVO NACIONAL. Sobre a Revista. Disponível em: http://revista.arquivonacional.gov.br/index.php/revistaacervo/. Acesso em: mar.2020. 
ÁGORA, Sobre a Revista. Disponível em: https://agora.emnuvens.com.br/ra. Acesso em: mar.2020.

ARQUIVO NACIONAL. Revista Arquivo \& Administração. Disponível em https://www.gov.br/arquivonacional/pt-

br/canais_atendimento/imprensa/noticias/revista-arquivo-administracao. Acesso em: mar.2020.

CAMARGO, A. M. de A. Arquivo, documento e informação: velhos e novos suportes. Arquivo \& Administração. Rio de Janeiro, v. 15-23; n. 1, p. 34-40, jan./dez. 1994.

CARLOMAGNO, M. C.; ROCHA, L. C. Como criar e classificar categorias para fazer análise de conteúdo: uma questão metodológica pesquisadores. Revista Eletrônica de Ciência Política, Curitiba, v. 7, n. 1, 2016.

CONSELHO NACIONAL DE ARQUIVOS (BR). Glossário: documentos arquivísticos digitais. 7 ed. Rio de Janeiro, 2016.

DOLLAR, C. O impacto das tecnologias de informação sobre princípios e práticas de arquivos: algumas considerações. Acervo. Revista do Arquivo Nacional. Rio de Janeiro. v. 7. n. 1 -2. p. 3-38, jan/dez 1994.

FISHBEIN, M. H. El comité de Automación del CIA: uma década de éxitos. ADPA, Madri, v. 4, n. 3, p. 9-14, 1984.

GOMES, C. M. Comunicação científica: alicerces, transformações e tendências. LivrosLabCom: Universidade da Beira Interior, Portugal, 2013.

JARDIM, J. M. As novas tecnologias da informação e o futuro dos arquivos.

Estudos Históricos. Rio de Janeiro, v. 5, n. 10, p. 251-260. 1992.

MARIZ, A. C. A. O correio eletrônico e o impacto na formação dos

arquivos empresariais: estudo dos casos da Shell e do Club Mediterranée. 1997. 100f. Dissertação (Mestrado em Memória Social e Documento) - Centro de Ciências Humanas, Universidade do Rio de Janeiro: UFRJ, 1997.

MEADOWS, A. J. A comunicação científica. Brasília: Briquet de Lemos, 1999.

CRUZ, Adelina Novaes e. No trilho da informação. Boletim da Associação dos Arquivistas Brasileiros. Rio de Janeiro, 2(1):2, 1992.

PAZ, Marilena Leite. Os arquivos e as novas tecnologias. Boletim da Associação dos Arquivistas Brasileiros. Rio de Janeiro, 7 (1/2):65:74, 1994. 
PAES, M. L. Os arquivos e os desafios de um mundo em mudanças. Acervo: revista do Arquivo Nacional, Rio de Janeiro, v. 7, n. 1/2, p. 65-74, jan./dez., 1994.

RONDINELLI, R. C. Gerenciamento Arquivístico de Documentos

Eletrônicos: uma abordagem teórica da diplomática arquivística contemporânea. Rio de Janeiro: FGV, 2002. 158 p.

\title{
THE SCIENTIFIC COMMUNICATION IN ARCHIVAL SCIENCE IN BRAZIL WITH THEMES RELATED TO DIGITAL TECHNOLOGY (2001-2018)
}

\begin{abstract}
Introduction: In the first decades of the 21 st century, more precisely between 2001 and 2018 , it is perceived through Brazilian scientific communication in the area of archival science that the widespread use of digital technology is increasingly influencing theoretical reflections, practices and methodological options archives. Objective: Based on this observation, the objective of this article is to identify, within the scope of the interrelationships between archives, archival science and digital technology, which are the themes that have aroused the interest of the professional and scientific community that writes and disseminates articles related to the subject. Methodology: The research is exploratory, descriptive and analytical in nature, based on a quantitative and qualitative survey of scientific articles available in the journals Acervo, Ágora, and Arquivo \& Administração, published between 2001 and 2018. Results: The results show that there is an increasing interest in the topic, especially related to the mutual influences that may exist between archives, archival science and digital technology. Conclusions: There are several theoretical and practical challenges in a disruptive technological context, whether due to the development of archival science in interlocution with the areas of information and communication, or due to the constant novelties imposed by technological development.
\end{abstract}

Descriptors: Archives. Archival Science. Digital technology. Journal Acervo. Journal Ágora. Journal Arquivo \& Administração.

\section{LA COMUNICACIÓN CIENTÍFICA DE ARCHIVÍSTICA EN BRASIL CON TEMAS RELACIONADOS CON LA TECNOLOGÍA DIGITAL (2001-2018)}

\section{RESUMEN}

Introdución: En las primeras décadas del siglo XXI, más precisamente entre 2001 y 2018, a través de la comunicación científica brasileña en el área de la archivística se percibe que el uso generalizado de la tecnología digital influye cada vez más en las reflexiones teóricas, las prácticas y las opciones metodológicas archivísticas. Objetivos: Con base en esta observación, el objetivo de este artículo es identificar, dentro del alcance de las interrelaciones entre archivos, archivística y tecnología digital, 
cuáles son los temas que han despertado el interés de la comunidad profesional y científica que escribe y difunde artículos relacionados con el tema. Metodología: La investigación es de naturaleza exploratoria, descriptiva y analítica, basada en una encuesta cuantitativa y cualitativa de artículos científicos disponibles en las revistas Acervo, Ágora y Arquivo \& Administração, publicadas entre 2001 y 2018. Resultados: Los resultados muestran que hay un aumento interés en el tema, especialmente relacionado con las influencias mutuas que pueden existir entre los archivos, la archivística y la tecnología digital. Conclusiones: Son varios los retos teóricos y prácticos en un contexto tecnológico disruptivo, ya sea debido al desarrollo de la archivística en la interlocución con las áreas de información y comunicación, o debido a las constantes novidades impuestas por el desarrollo tecnológico.

Descriptores: Archivos. Archivística. Tecnología Digital. Revista Ágora. Revista Arquivo \& Administração. Revista Acervo.

Recebido em: 04.03.2020

Aceito em: 10.09 .2020 